\title{
Mepolizumab for Eosinophil-Associated COPD: Analysis of METREX and METREO
}

\author{
lan D Pavord (iD) \\ Kenneth R Chapman $\mathbb{D}^{2}$ \\ Mona Bafadhel (D) \\ Frank C Sciurba ${ }^{3}$ \\ Eric S Bradford ${ }^{4}$ \\ Stephanie Schweiker Harris ${ }^{4}$ \\ Bhabita Mayer ${ }^{5}$ \\ David B Rubin ${ }^{4}$ \\ Steven W Yancey ${ }^{4}$ \\ Pierluigi Paggiaro ${ }^{6}$ \\ 'Nuffield Department of Medicine and \\ Oxford Respiratory NIHR BRC, University \\ of Oxford, Oxford, UK; ${ }^{2}$ Asthma \& Airway \\ Centre, UHN and University of Toronto, \\ Toronto, ON, Canada; ${ }^{3}$ Department of \\ Medicine, University of Pittsburgh, \\ Pittsburgh, PA, USA; ${ }^{4}$ Respiratory \\ Therapeutic Area, GSK, Research Triangle \\ Park, NC, USA; ${ }^{5}$ Clinical Statistics, GSK, \\ Brentford, Middlesex, UK; ${ }^{6}$ Department of \\ Surgery, Medicine, Molecular Biology, and \\ Critical Care, University of Pisa, Pisa, Italy
}

Correspondence: lan D Pavord NDM Research Building, Nuffield Department of Medicine and Oxford Respiratory NIHR BRC, University of Oxford, Old Road Campus, Roosevelt Drive, Oxford, OX3 7FZ, UK

Tel +44I865 6I2897

Email ian.pavord@ndm.ox.ac.uk
Background: A pre-specified meta-analysis of individual patient data from the 52-week METREX and METREO trials, which investigated mepolizumab for chronic obstructive pulmonary disease (COPD) in patients with blood eosinophil counts $\geq 150$ cells $/ \mu \mathrm{L}$ (screening) or $\geq 300$ cells $/ \mu \mathrm{L}$ (prior year) and frequent exacerbations, enables more robust characterization of mepolizumab efficacy in COPD and exploration of the relationship between blood eosinophil count and treatment responses.

Methods: In METREX (117106/NCT02105948) and METREO (117113/NCT02105961), randomized patients received mepolizumab or placebo added to existing inhaled corticosteroid (ICS)-based triple maintenance therapy. The annual rate of moderate/severe exacerbations (primary endpoint) was compared between subcutaneous (SC) mepolizumab $100 \mathrm{mg}$ versus placebo (primary comparison of interest) and all doses (100 mg and $300 \mathrm{mg} \mathrm{SC})$ versus placebo in patients with blood eosinophil counts $\geq 150$ cells $/ \mu \mathrm{L}$ at screening or $\geq 300$ cells $/ \mu \mathrm{L}$ in the prior year. Secondary/other endpoints included time to first moderate/severe exacerbation, exacerbations leading to emergency department visit/hospitalization and health-related quality of life (HRQoL). A predictive model of the relationship between screening blood eosinophil counts and exacerbation rates included data from all randomized patients.

Results: In total, 1510 patients were randomized in METREX and METREO and 1136 patients were included in the pre-specified meta-analysis. From the meta-analysis, mepolizumab $100 \mathrm{mg}$ SC significantly reduced annual moderate/severe exacerbation rates versus placebo by $18 \%$ (rate ratio: 0.82 ; $95 \%$ confidence interval: $0.71,0.95 ; \mathrm{p}=0.006)$ and delayed time to first moderate/ severe exacerbation (hazard ratio: 0.80 [0.68, 0.94]; $\mathrm{p}=0.006$ ). Mepolizumab $100 \mathrm{mg} \mathrm{SC}$ versus placebo numerically reduced exacerbations leading to ED visits/hospitalization and improved HRQoL. A modelling approach demonstrated increasing efficacy for moderate/severe exacerbations with increasing screening blood eosinophil count; this relationship was more pronounced for exacerbations requiring oral corticosteroids (post hoc). The all-doses comparison had similar results.

Conclusion: Mepolizumab reduces exacerbations in patients with eosinophil-associated COPD. Results suggest that blood eosinophil counts $(\geq 150$ cells $/ \mu \mathrm{L}$ at screening or $\geq 300$ cells $/ \mu \mathrm{L}$ in the prior year) allow for identification of patients with COPD who experience exacerbations while treated with maximal ICS-based triple maintenance therapy who are likely to benefit from mepolizumab.

Keywords: mepolizumab, COPD, eosinophil, exacerbation

\section{Plain Language Summary}

Chronic obstructive pulmonary disease (COPD) is a lung condition. Some patients with COPD can have lots of flares of their symptoms (also called exacerbations) even if they take their usual inhalers. These flares can require extra treatment or visits to the hospital. Some 
patients with COPD also have an increased number of a type of white blood cell called the eosinophil. Mepolizumab is a drug that works by reducing the number of eosinophils in the blood. This may help reduce the number of flares. Therefore, mepolizumab may help patients with COPD and an increased number of eosinophils in the blood. METREX and METREO were studies that looked at how well mepolizumab works in these patients. As analyses with more patients can strengthen the results, the analysis in our paper combined the data from both studies.

This analysis showed that mepolizumab reduced the number of COPD flares that needed antibiotics or steroid tablets. The number of patients who went to hospital was also reduced by about one fifth. Quality of life was improved. Mepolizumab worked better in patients who had higher numbers of eosinophils in the blood before they were given mepolizumab. Mepolizumab also worked better for patients whose flares were treated with steroid tablets compared with antibiotics.

These results suggest that mepolizumab works in patients with COPD who have flares despite taking their usual inhalers. They also suggest that the number of eosinophils in a patient's blood may help doctors decide if mepolizumab will work for them.

\section{Introduction}

Eosinophils may be involved in the pathogenesis of chronic obstructive pulmonary disease (COPD) and associated exacerbations. ${ }^{1-3}$ Sputum eosinophilia ( $>3 \%$ nonsquamous cells) has been observed in approximately onethird of patients during an exacerbation, ${ }^{3}$ and sputum eosinophil counts are associated with COPD severity. ${ }^{4,5}$ Sputum eosinophils can also identify patients more likely to respond to corticosteroid treatment.,

Blood eosinophil counts correlate positively with sputum eosinophil counts, with counts of $<2 \%$ (equivalent to approximately $<150$ cells $/ \mu \mathrm{L})^{7}$ having a high negative predictive value in stable and exacerbating COPD. ${ }^{8-10}$ Although correlations between blood and sputum eosinophil counts are reported to be lower in COPD than asthma, potentially due to the presence of comorbidities, ${ }^{11}$ patients with higher blood eosinophil counts have a greater response to corticosteroid therapy in COPD. ${ }^{12-14}$ This indicates that measurement of blood eosinophil counts may be useful biomarker of the efficacy of therapies targeting eosinophilic inflammation. ${ }^{14}$

Mepolizumab is a humanized monoclonal antibody that binds to and inactivates interleukin-5, reducing blood eosinophils to normal levels. ${ }^{15,16}$ Clinical trials of mepolizumab in severe eosinophilic asthma demonstrated reduced exacerbation frequency and improvements in disease burden, particularly in patients with higher blood eosinophil counts. ${ }^{17-21}$ In COPD, the METREX and METREO trials investigated mepolizumab in patients with COPD who continued to experience exacerbations despite receiving maximal inhaled corticosteroid (ICS)-based triple maintenance therapy for $\geq 12$ months prior to the study. ${ }^{21}$ In both trials, compared with placebo, mepolizumab $100 \mathrm{mg}$ subcutaneously (SC) added to triple therapy produced clinically meaningful reductions $(18-20 \%)^{22}$ in mean annual moderate/severe exacerbation rates; these differences were statistically significant in METREX, but not in METREO following the pre-specified correction for multiplicity. ${ }^{21}$ The effect of mepolizumab on other key outcomes, such as exacerbations leading to emergency department (ED) visits/ hospitalization and St George's Respiratory Questionnaire (SGRQ) total score versus placebo, varied between trials. ${ }^{21}$ Mepolizumab treatment effects on moderate/severe exacerbations were found to increase with increasing blood eosinophil counts; the relationship between other study outcomes and blood eosinophil counts remains to be determined.

We performed a pre-specified meta-analysis of patient level data from METREX and METREO of individuals with COPD and blood eosinophil counts $\geq 150$ cells $/ \mu \mathrm{L}$ at screening or $\geq 300$ cells $/ \mu \mathrm{L}$ in the prior year. Mepolizumab $100 \mathrm{mg}$ SC was the proposed licensed dose; its comparison with placebo is the primary focus of this manuscript. The aims were to provide more robust estimates of the effect of mepolizumab compared with placebo on COPD outcomes including exacerbation rates and quality of life, and to fully explore the relationship between blood eosinophil count and treatment responses.

\section{Methods}

\section{Study Design}

METREX (117106/NCT02105948) and METREO (117113/ NCT02105961) were Phase III, placebo-controlled, randomized, double-blind, multicenter trials. Detailed information regarding the trials, including study designs (Figure E1) has been published previously (see also Supplementary Materials) ${ }^{21}$ Briefly, eligible patients were randomized 1:1 in METREX to receive mepolizumab $100 \mathrm{mg}$ or placebo SC, and 1:1:1 in METREO to receive mepolizumab 100 or $300 \mathrm{mg}$, or placebo SC every 4 weeks for 52 weeks (final dose at Week 48), while continuing existing standard of care: triple inhaled therapy consisting of high-dose ICS $(\geq 500 \mu \mathrm{g}$ ) day of fluticasone propionate or equivalent), a long-acting 
$\beta_{2}$-agonist (LABA) and a long-acting muscarinic-receptor antagonist (LAMA). This meta-analysis included patients from both trials with blood eosinophil counts $\geq 150$ cells $/ \mu \mathrm{L}$ at screening or $\geq 300$ cells $/ \mu \mathrm{L}$ in the prior year. Inclusion of data from METREX and METREO was pre-specified for this meta-analysis. Consequently, data from a pilot trial of mepolizumab in patients with COPD and chronic bronchitis was not included as the eligibility criteria were different to METREX/METREO. ${ }^{23}$

\section{Patients}

Eligible patients were aged $\geq 40$ years with a documented diagnosis of COPD for $\geq 1$ year, ${ }^{24}$ required a pre- and postbronchodilator forced expiratory volume in $1 \mathrm{~s}\left(\mathrm{FEV}_{1}\right)$ /forced vital capacity ratio $<0.70$ and a postbronchodilator $\mathrm{FEV}_{1}>20-\leq 80 \%$ of predicted and a history of $\geq 2$ moderate (requiring antibiotics and/or systemic corticosteroids) or $\geq 1$ severe (leading to hospitalization) exacerbations in the prior year despite being on ICS-based therapy. Full eligibility criteria have been published previously. ${ }^{21}$

\section{Endpoints and Assessments}

The primary meta-analysis endpoint was the annual rate of moderate or severe exacerbations. Secondary and other endpoints included annual rates of exacerbations leading to ED visit/hospitalization; annual rates of severe exacerbations; time to first moderate/severe exacerbation; time to first exacerbation leading to ED visit/hospitalization; health-related quality of life (HRQoL) including Week 52 change from baseline in COPD-specific SGRQ total (domain [symptoms, activity and impacts]) and COPD Assessment Test (CAT) scores, and the proportion of SGRQ and CAT (post hoc) responders ( $\geq 4$-point and $\geq 2$-point decrease from baseline, respectively; the minimal clinically important difference [MCID] for each measure) ${ }^{25,26}$ patient- and clinician-rated response to therapy and change from baseline in pre-bronchodilator $\mathrm{FEV}_{1}$.

Endpoints were assessed by screening blood eosinophil count thresholds: $<150$ ( $\geq 300$ in prior year), $\geq 150, \geq 300$, $\geq 500$ cells $/ \mu \mathrm{L}$ and categories: $<150$ ( $\geq 300$ in prior year), $\geq 150-<300, \geq 300-<500, \geq 500$ cells $/ \mu \mathrm{L}$. A post hoc analysis of moderate/severe exacerbations requiring antibiotics (with and without OCS) and exacerbations requiring OCS (with and without antibiotics) by eosinophil category was also performed. Statistical modelling of the relationship between screening blood eosinophils and treatment effect on moderate/severe exacerbations and the post hoc analysis of exacerbations requiring corticosteroids included all randomized patients from METREX and METREO. Analyses were pre-specified unless otherwise stated.

\section{Statistical Analyses}

The primary analysis population for the meta-analysis was the modified intent-to-treat population: all randomized patients receiving $\geq 1$ dose of study medication with a blood eosinophil count $\geq 150$ cells $/ \mu \mathrm{L}$ (screening) or $\geq 300$ cells $/ \mu \mathrm{L}$ (prior year). This meta-analysis evaluated mepolizumab $100 \mathrm{mg} \mathrm{SC}$ (primary comparison of interest), and all doses (100 and $300 \mathrm{mg}$ SC combined; described in Supplementary Materials), versus placebo. A two-sided unadjusted significance level of $\alpha=0.05$ was employed. Exacerbations were analyzed using negative binomial (rate/year) and Cox proportional hazards (time to first) models, SGRQ and CAT using mixed model repeated measures (change from baseline) and logistic regression (responders), patient- and clinician-rated responses using multinomial (ordered) logistic regression. Predictive modelling of exacerbation rate reductions and eosinophils used post hoc fractional polynomial modelling. Additional details are available in Supplementary Materials.

\section{Results \\ Patient Population}

In total, of the 1510 patients randomized in METREX and METREO, 1136 patients with blood eosinophil counts $\geq 150$ cells $/ \mu \mathrm{L}$ at screening or $\geq 300$ cells $/ \mu \mathrm{L}$ in the prior year were included in the meta-analysis (mepolizumab 100 mg: $\mathrm{N}=456$; mepolizumab $300 \mathrm{mg} \mathrm{SC}$ : $\mathrm{N}=225$; placebo: $\mathrm{N}=455$ ). Results for the all-dose comparison including patients receiving the $300 \mathrm{mg}$ dose of mepolizumab are presented in the Supplementary Materials. For the modelling analysis, the additional 374 patients from METREX with eosinophil count $<150$ cells $/ \mu \mathrm{L}$ at screening and no evidence of $\geq 300$ cells $/ \mu \mathrm{L}$ in the previous year were also included $(\mathrm{N}=1510)$.

From the meta-analysis, 90 (8\%) patients prematurely discontinued treatment and remained in the trial (mepolizumab 100/300 mg SC: 31 [7\%]/19 [8\%]; placebo: 40 [9\%]). Patients had a high disease burden, with $\geq 94 \%$ classified as having disease meeting the criteria for GOLD (Global Initiative for Chronic Obstructive Lung Disease) group D COPD, a mean annual 
exacerbation rate (prior year) of 2.6 events/year and mean baseline SGRQ and CAT scores of 53.0-54.7 and 18.6-19.5, respectively (Table 1, Table E1). The proportions of non-smokers $(\sim 3 \%)$ were similar between groups; in a post hoc analysis, baseline blood eosinophil counts were similar for patients who were current smokers (geometric mean [standard deviation logs]: 260 [0.592] cells $/ \mu \mathrm{L}$ ) compared with those who were exsmokers or who had never smoked (240 [0.805] cells/ $\mu \mathrm{L})$. Results presented below were similar when nonsmokers were excluded (data not shown).

\section{Exacerbation Rates}

Mean annual moderate/severe exacerbation rates were 1.32 and 1.61 events/year following treatment with mepolizumab $100 \mathrm{mg} \mathrm{SC}$ and placebo, respectively, added to triple inhaled therapy. Mepolizumab $100 \mathrm{mg}$ SC significantly reduced annual moderate/severe exacerbation rates by $18 \%$ versus placebo (rate ratio [RR]: $0.82 ; 95 \%$ confidence interval $[\mathrm{CI}]: 0.71,0.95 ; \mathrm{p}=0.006$ ) (Figure 1, Table E2). In total, $18 \%$ and $22 \%$ of patients in the mepolizumab $100 \mathrm{mg} \mathrm{SC}$ and placebo groups, respectively, experienced $\geq 1$ exacerbation leading to ED visit/hospitalization. The RR with mepolizumab $100 \mathrm{mg}$ SC versus placebo was 0.85 (95\% CI: 0.61, 1.18; $\mathrm{p}=0.328$ ) for exacerbations leading to $\mathrm{ED}$ visit/hospitalization, and 0.88 (95\% CI: $0.62,1.25 ; \mathrm{p}=0.475$ ) for severe exacerbations.

Time to first moderate/severe exacerbation was significantly longer with mepolizumab $100 \mathrm{mg}$ SC than placebo (Kaplan-Meier median time to first moderate/severe exacerbation: 218 vs 155 days, respectively; hazard ratio [HR]: 0.80; 95\% CI: 0.68, 0.94; $\mathrm{p}=0.006$ ) (Figure 2, Table E2). Time to first exacerbation leading to ED visit/hospitalization was numerically longer with mepolizumab 100 mg SC than placebo (HR: 0.81; 95\% CI: 0.61, 1.09; $\mathrm{p}=0.170$ ) (Figure 2, Table E2).

\section{HRQoL}

Improvements from baseline in SGRQ total score were initially greater with mepolizumab $100 \mathrm{mg} \mathrm{SC}$ versus placebo (Week 12 difference: -1.5 ; 95\% CI: $-3.1,0.0$; Week 24 difference: -3.4 ; 95\% CI: $-5.2,-1.6)$ but this was not sustained at Week 52 (difference: -0.7 ; 95\% CI: $-2.7,1.3$; $\mathrm{p}=0.486$ ) (Figure 3, Table E3). A similar trend was observed with the activity and impact domains (Table E3). Symptom domain scores were significantly improved from baseline with mepolizumab $100 \mathrm{mg} \mathrm{SC}$ at all time points except Week 32 (Week 52 difference: -2.9 ; 95\% CI: $-5.3,-0.5 ; \mathrm{p}=0.020$ )
(Table E3). There were more SGRQ responders with mepolizumab $100 \mathrm{mg}$ SC than with placebo at all time points; at Week 52 : $42 \%$ versus $32 \%$ (odds ratio [OR]: $1.23 ; 95 \% \mathrm{CI}$ : 0.94, 1.61; $\mathrm{p}=0.138$ ) (Figure 3, Table E3).

Improvements from baseline in CAT score were greater with mepolizumab $100 \mathrm{mg}$ SC versus placebo throughout the study (Figure 3), with a significant difference at Week 52 (difference: $-0.9 ; 95 \%$ CI: $-1.8,0 ; \mathrm{p}=0.039$ ) (Table E3); the proportion of CAT responders was also greater throughout the study, with $39 \%$ and $33 \%$ of responders at Week 52, respectively (OR: 1.39; 95\% CI: 1.04, 1.85; $\mathrm{p}=0.024$ ) (Figure 3, Table E3).

\section{Patient- and Clinician-Rated Response to Therapy}

At Week 52, 56\% and 50\% of patients in the mepolizumab $100 \mathrm{mg} \mathrm{SC}$ and placebo groups rated themselves improved (OR: $1.26 ; 95 \% \mathrm{CI}: 0.97,1.63 ; \mathrm{p}=0.077$ ) and $53 \%$ and $44 \%$ were rated improved by their clinicians (OR: 1.41; 95\% CI: 1.09, 1.83; $\mathrm{p}=0.008$ ), respectively (Table E4).

\section{Lung Function}

Changes from baseline in pre-bronchodilator $\mathrm{FEV}_{1}$ were small throughout the study with mepolizumab $100 \mathrm{mg} \mathrm{SC}$ and placebo (difference: $5-31 \mathrm{~mL}$ across all time points) (Figure E2, Table E5).

\section{Stratification by Eosinophil Thresholds}

Treatment benefits with mepolizumab $100 \mathrm{mg}$ SC versus placebo increased with increasing screening blood eosinophil counts (Figures 4 and 5) for the annual rate of moderate/ severe exacerbations, exacerbations leading to ED visit/hospitalization, SGRQ total scores and SGRQ responders. This relationship was apparent to a lesser extent for severe exacerbations, CAT score and CAT responders (Figures 4 and 5). The analysis of endpoints by blood eosinophil categories yielded broadly consistent results (Tables E6-8).

In total, 1510 patients (mepolizumab $100 \mathrm{mg}$ : $\mathrm{N}=640$; mepolizumab $300 \mathrm{mg}$ : $\mathrm{N}=225$; placebo: $\mathrm{N}=645$; [836 from METREX (including patients with $<150$ cells $/ \mu \mathrm{L}$ at screening and no evidence of $\geq 300$ in prior year) and 674 from METREO]) were included in the eosinophil response modelling. Predicted annual moderate/severe exacerbation rates increased with increasing screening blood eosinophil counts in the placebo group and remained relatively stable across screening blood eosinophil counts in the mepolizumab 100 mg group (Figure 6). Predicted exacerbation rate reductions 
Table I Patient Demographics and Clinical Characteristics at Baseline

\begin{tabular}{|c|c|c|}
\hline Characteristic & Mepolizumab 100 mg SC ( $=456)$ & Placebo $(\mathrm{N}=455)$ \\
\hline Age, years, mean (SD) & $65(9)$ & $66(9)$ \\
\hline $\begin{array}{l}\text { Gender, n (\%) } \\
\text { Female }\end{array}$ & $175(38)$ & $149(33)$ \\
\hline $\begin{array}{l}\text { Smoking history screening, pack-years, mean (SD) } \\
\text { Non-smoker, n (\%) } \\
\text { Former, n (\%) } \\
\text { Current, n (\%) }\end{array}$ & $\begin{array}{l}42.6(25.0) \\
12(3) \\
327(72) \\
117(26)\end{array}$ & $\begin{array}{l}46.3(27.1) \\
13(3) \\
307(67) \\
135(30)\end{array}$ \\
\hline Duration of COPD, years, mean (SD) & $9.0(6.6)$ & $9.1(6.1)$ \\
\hline Patients on maintenance oral corticosteroids, $\mathrm{n}(\%)$ & $25(6)$ & $17(4)$ \\
\hline $\begin{array}{l}\text { Moderate/severe exacerbations } \\
\text { In prior year, mean events (SD) } \\
\geq \text { I moderate exacerbation, } \mathrm{n}(\%) \\
\geq \text { I severe exacerbation, } \mathrm{n}(\%)\end{array}$ & $\begin{array}{l}2.6(1.4) \\
391(86) \\
152(33)\end{array}$ & $\begin{array}{l}2.6(1.3) \\
379(83) \\
161(35)\end{array}$ \\
\hline GOLD group D, n (\%) & $430(94)$ & $434(95)$ \\
\hline $\begin{array}{l}\text { Severity of airflow limitation, } \mathrm{n}(\%) \\
\text { Mild: } \geq 80 \% \text { predicted } \\
\text { Moderate: } \geq 50-<80 \% \text { predicted } \\
\text { Severe: } \geq 30-<50 \% \text { predicted } \\
\text { Very severe: }<30 \% \text { predicted }\end{array}$ & $\begin{array}{l}6(1) \\
169(37) \\
210(46) \\
71(16)\end{array}$ & $\begin{array}{l}4(<1) \\
156(34) \\
217(48) \\
78(17)\end{array}$ \\
\hline $\begin{array}{l}\text { Screening blood eosinophil counts, cells/ } \mu \mathrm{L}, \mathrm{n} \text { (\%) } \\
\text { Thresholds }\end{array}$ & & \\
\hline $\begin{array}{l}<150 \text { (and } \geq 300 \text { in the prior year) } \\
\geq 150 \\
\geq 300 \\
\geq 500\end{array}$ & $\begin{array}{l}53(12) \\
402(88) \\
165(36) \\
53(12)\end{array}$ & $\begin{array}{l}42(9) \\
412(91) \\
177(39) \\
67(15)\end{array}$ \\
\hline $\begin{array}{l}\text { Categories } \\
\quad \geq 150-<300 \\
\quad \geq 300-<500 \\
\text { Geometric mean (SD logs) }\end{array}$ & $\begin{array}{l}237(52) \\
112(25) \\
240(0.729)\end{array}$ & $\begin{array}{l}235(52) \\
110(24) \\
250(0.739)\end{array}$ \\
\hline $\begin{array}{l}\text { Health-related quality of life at baseline } \\
\text { SGRQ total score, mean (SD) } \\
\text { CAT score, mean (SD) }\end{array}$ & $\begin{array}{l}53.0(17.5) \\
18.6(7.6)\end{array}$ & $\begin{array}{l}54.7(16.0) \\
19.5(7.6)\end{array}$ \\
\hline
\end{tabular}

Abbreviations: CAT, COPD Assessment Test; COPD, chronic obstructive pulmonary disease; GOLD, Global Initiative for Chronic Obstructive Lung Disease; SC, subcutaneous; SD, standard deviation; SGRQ, St George's Respiratory Questionnaire.

were greater with mepolizumab $100 \mathrm{mg}$ versus placebo as screening blood eosinophil counts increased, with a predicted 14\% reduction (RR: $0.86 ; 95 \%$ CI: $0.75,0.99$ ) at 300 cells/ $\mu \mathrm{L}$, a $23 \%$ reduction (RR: 0.77 ; 95\% CI: $0.63,0.93$ ) at 500 cells $/ \mu \mathrm{L}$ and a $30 \%$ reduction (RR: $0.70 ; 95 \% \mathrm{CI}: 0.55,0.90)$ at 750 cells $/ \mu \mathrm{L}$ (Figure 6). RR predictions were consistent with blood eosinophil category results (Table E9).

For exacerbations requiring treatment with corticosteroids, predicted annual moderate/severe exacerbation rates can be seen in Figure 7A and eosinophil response modelling-predicted rate reductions were $22 \%$ at 300 cells $/ \mu \mathrm{L}$,
$35 \%$ at 500 cells $/ \mu \mathrm{L}$ and $43 \%$ at 500 cells/ $\mu \mathrm{L}$ (Figure $7 \mathrm{~B}$ ). For the analysis of moderate/severe exacerbations requiring antibiotics, no clear relationship between treatment effect and blood eosinophil category was observed (Figure 7C), so further modelling was not carried out.

\section{Endpoints for the Mepolizumab All-Doses Group}

Similar results to mepolizumab $100 \mathrm{mg}$ SC versus placebo were observed in the mepolizumab all-doses group versus 


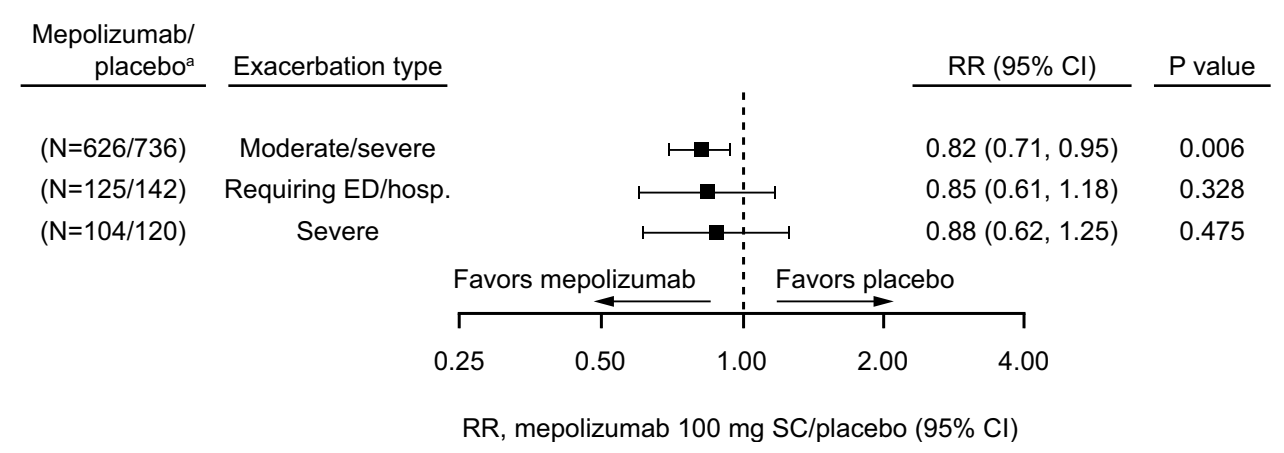

Figure I Reduction in annual rate of exacerbations. ${ }^{a}$ Numbers indicate number of exacerbations experienced in each group. Abbreviations: $\mathrm{Cl}$, confidence interval; ED, emergency department; hosp., hospital; RR, rate ratio; SC, subcutaneous.

placebo for all endpoint comparisons (Tables E2-E8) and the analysis of exacerbations by treatment type (data on file).

\section{Discussion}

Overall, the results of this meta-analysis demonstrated a progressive increase in mepolizumab efficacy versus placebo with increasing blood eosinophil counts for most outcome measures, particularly in patients with $\geq 300$ cells $/ \mu \mathrm{L}$. Building on the eosinophil subgroup analysis reported previously, ${ }^{21}$ predictive modelling analysis demonstrated rate reductions with mepolizumab versus placebo for moderate/severe exacerbations that increased with increasing blood eosinophil counts, consistent with previous studies. ${ }^{27,28}$ This is also consistent with an analysis of two large studies of benralizumab in COPD, the latter of which found that blood eosinophil counts $\geq 220$ cells $/ \mu \mathrm{L}$ were predictive of reduced exacerbation frequency, particularly in patients with $\geq 3$ exacerbations in the prior year. ${ }^{19,29}$ Together, these results support the utility of blood eosinophil counts to identify patients with COPD responsive to anti-IL-5 treatment, although this population may require further refinement to determine the patients most likely to be responsive to treatment.

In general, larger mepolizumab versus placebo reductions were predicted for exacerbations requiring treatment with corticosteroids with increasing blood eosinophil count, whereas exacerbations requiring antibiotics showed no clear trend. Previously, a cluster analysis identified biologically distinct infection-related and eosinophil-associated exacerbation types distinguishable by the presence of raised blood eosinophil counts. ${ }^{3}$ Moreover, differential treatment responses to bronchodilator therapy with OCS-treated and antibiotic-treated exacerbations have also been demonstrated. ${ }^{30}$ With the current results, this suggests that exacerbation subtypes may be differentially responsive to specific inhibition of eosinophilic airway inflammation; future studies should investigate this possibility.

In the meta-analysis, mepolizumab treatment in addition to triple inhaled therapy resulted in an $18 \%$ reduction in annual moderate/severe exacerbation rates and delayed the time to first moderate/severe exacerbation versus placebo. This was coupled with mepolizumab-treated patients being significantly more likely to report clinically important improvements in CAT score and numerically more likely to report a clinically important improvement in SGRQ score and be in a higher improvement response category based on clinician assessment than placebo-treated patients. These findings suggest that mepolizumab treatment has clinical benefits in patients with eosinophil-associated COPD who have a history of exacerbations despite maximal ICS-based triple maintenance therapy and limited further treatment options.

All exacerbation types reported were numerically reduced with mepolizumab over placebo by $12-18 \%$, which is consistent with the range of exacerbation rate reductions observed in previous COPD studies $(8-35 \%) .{ }^{31-37}$ Exacerbation reductions in this metaanalysis should be considered in the context of being additional to reductions in exacerbations from ICS/ LABA/LAMA triple therapy, which was a protocolrequired background treatment for all patients. Previous studies have demonstrated moderate/severe exacerbation reductions with monotherapy versus placebo of $11-18 \%$, dual therapy versus placebo of $25-29 \%$, dual therapy versus monotherapy of $9-30 \%$ and triple therapy versus dual therapy of $8-35 \%{ }^{31-37}$ These results can be considered clinically meaningful in the context of the suggested MCID for COPD exacerbation reduction of $11 \%{ }^{22}$ 
A
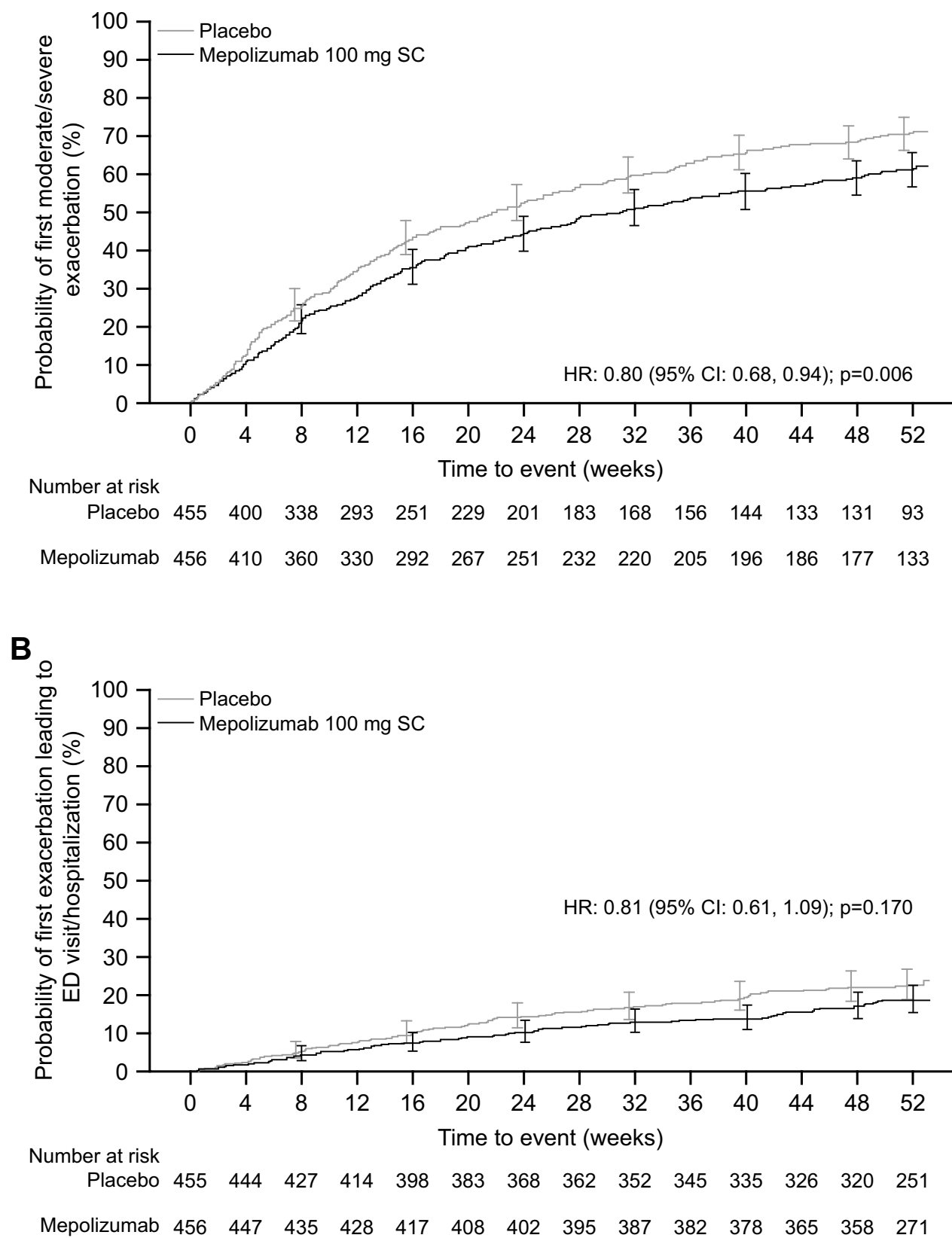

Figure 2 Kaplan-Meier curve of $(\mathbf{A})$ time to first moderate/severe exacerbation and (B) time to first exacerbation leading to ED visit/hospitalization. Vertical bars represent 95\% Cls.

Abbreviations: $\mathrm{Cl}$, confidence interval; $\mathrm{ED}$, emergency department; SC, subcutaneous.

The findings highlight the utility of meta-analyses in gaining further insights from observed data. METREX and METREO were designed on the basis of treatment effects observed in previous studies of patients with severe eosinophilic asthma, ${ }^{17,20}$ with each study being powered at $90 \%$ based on an expected placebo rate of 2.0 moderate/severe exacerbations/year and a true population reduction of $35 \%$ with mepolizumab treatment. In METREX and METREO, the observed reductions in moderate/severe exacerbation rates with mepolizumab $100 \mathrm{mg}$ SC of $18 \%$ and $20 \%$, respectively and the exacerbation rates with placebo (1.71 and 1.49/year, respectively) were lower than expected. ${ }^{21}$ Additionally, moderate/severe exacerbations were reduced by $14 \%$ with mepolizumab $300 \mathrm{mg} \mathrm{SC}$ versus placebo in 
A

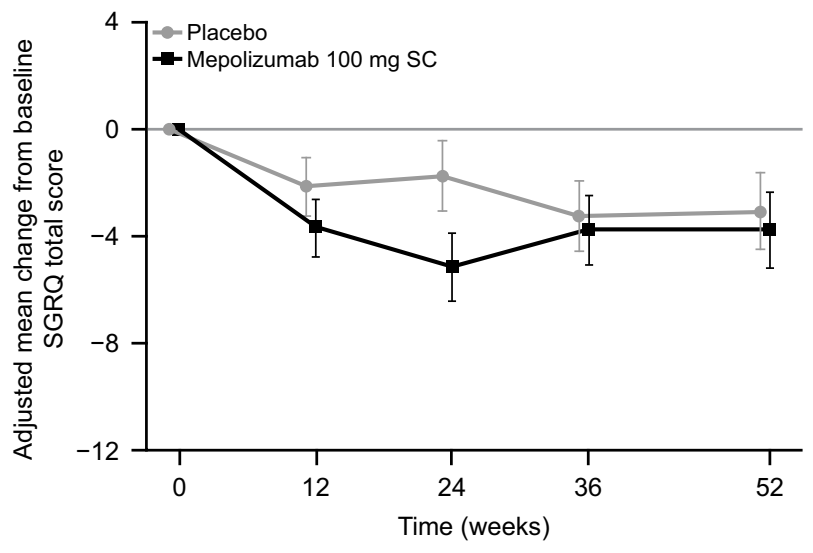

C

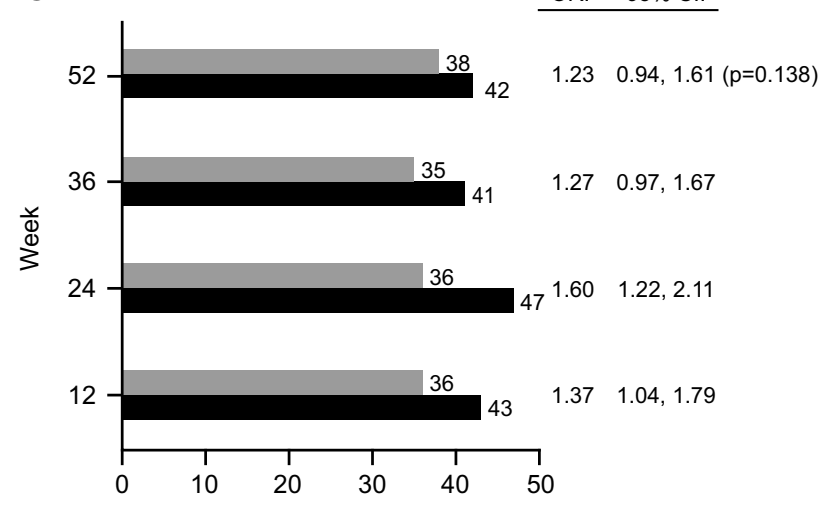

Proportion of SGRQ responders (\%)

- Placebo Mepolizumab $100 \mathrm{mg} \mathrm{SC}$
B

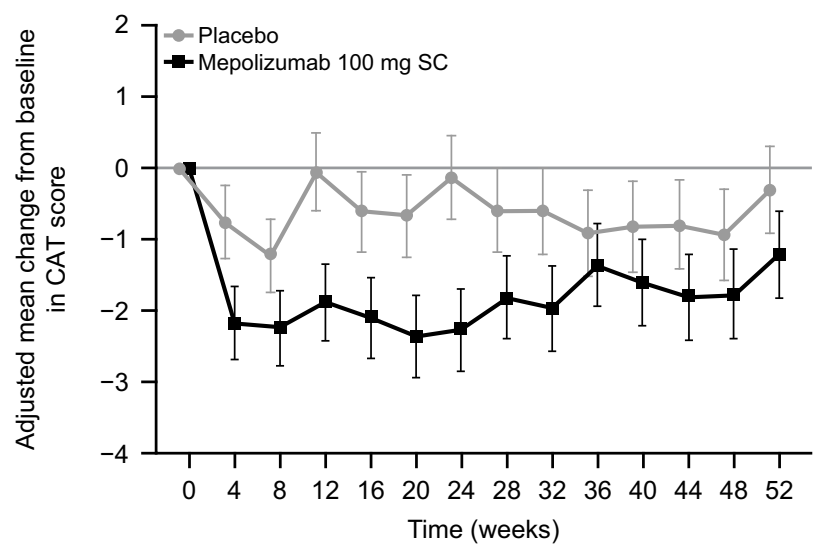

D

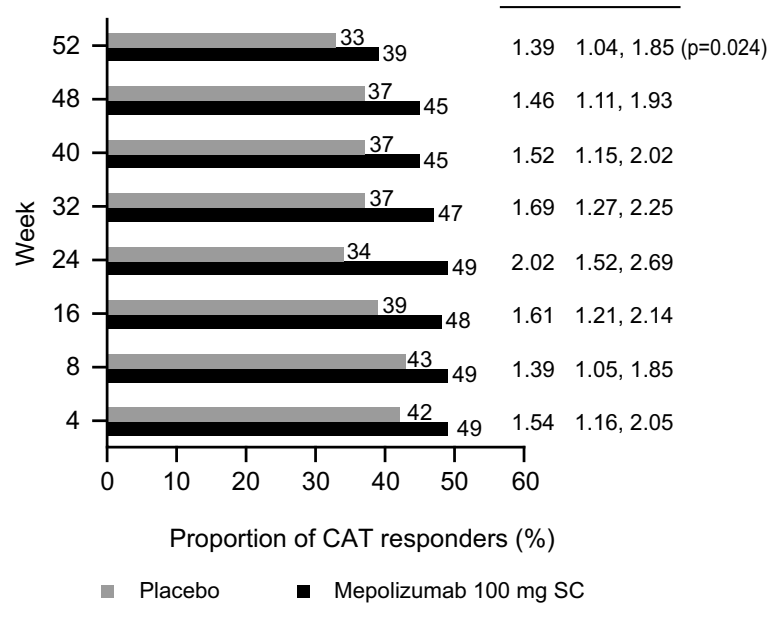

Figure 3 Change from baseline for (A) SGRQ total score and (B) CAT score, and (C) proportion of SGRQ responders ${ }^{\mathrm{a}}$ and (D) CAT responders ${ }^{\mathrm{b}}$. In panels A and B, the vertical bars represent $95 \% \mathrm{Cls}$. ${ }^{\text {SSGRQ }}$ responders are defined as patients achieving $\geq 4$-point reduction in total score; ${ }^{\mathrm{b}} \mathrm{CAT}$ responders are defined as patients achieving a $\geq 2$-point decrease from baseline.

Abbreviations: CAT, COPD Assessment Test; Cl, confidence interval; COPD, chronic obstructive pulmonary disease; OR, odds ratio; SC, subcutaneous; SGRQ, St George's Respiratory Questionnaire.

METREO, suggesting no additional benefit with mepolizumab doses greater than $100 \mathrm{mg} \mathrm{SC}{ }^{21}$ This meta-analysis has allowed for greater precision in estimating the rate reductions in moderate/severe exacerbations by blood eosinophil count and evaluating treatment effects with mepolizumab $100 \mathrm{mg}$ $\mathrm{SC}$ for more infrequent events, such as exacerbations leading to ED visits/hospitalization and severe exacerbations.

Exacerbations can have a significant impact on HRQoL; mepolizumab-treated patients showed improvements from baseline in HRQoL from the earliest postbaseline assessments, and maximum reductions were reached within 24 weeks, as noted in other studies. ${ }^{38,39}$ By Week 52, only changes in CAT score were significant compared with placebo. Differences between SGRQ and
CAT results are likely a reflection of differences in assessment and specificity of the two measures. ${ }^{40,41}$ Decreased differentiation between treatment groups of HRQoL responses over time may be partly related to the disproportionate patient dropout rate and times in the placebo versus the mepolizumab $100 \mathrm{mg}$ SC group, as has been previously reported in the 3 -year TORCH trial. $^{42}$ Unexpectedly, SGRQ improvements from baseline approached the MCID at Week 52 in both the placebo $\left(-3.1\right.$ points) and mepolizumab ( -3.8 points) groups ${ }^{25}$ these were similar to improvements ( -1.9 to -5.5 points) observed in previous 52-week studies of bronchodilator and ICS combination therapy in patients with severe COPD. ${ }^{34,37}$ When assessing the number of patients 


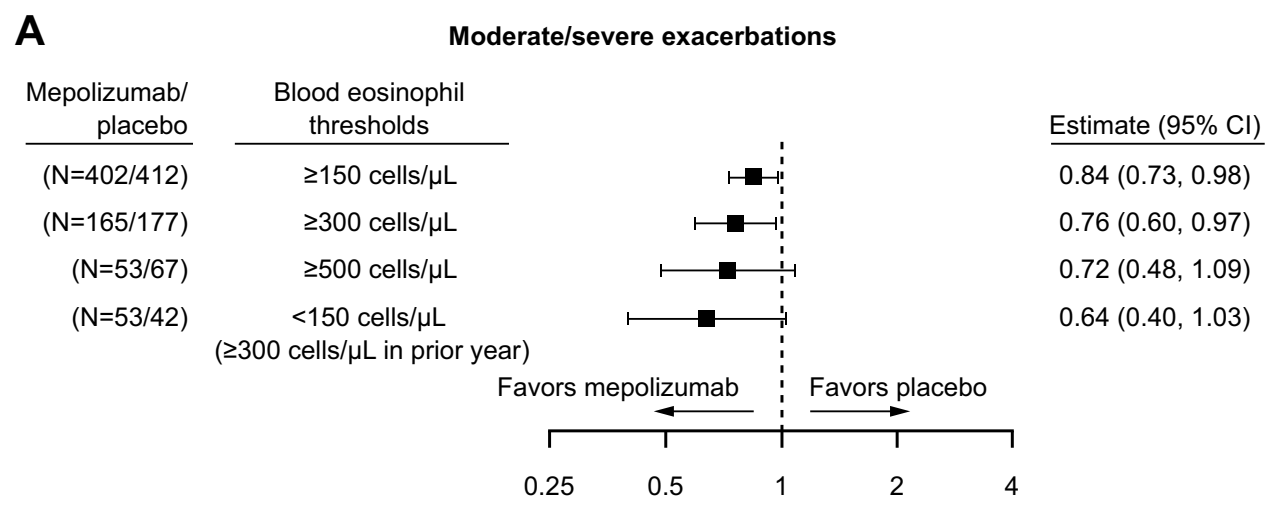

RR, mepolizumab $100 \mathrm{mg} \mathrm{SC/placebo} \mathrm{(95 \%} \mathrm{Cl)}$

\section{B}

\begin{tabular}{rcc}
$\begin{array}{r}\text { Mepolizumab/ } \\
\text { placebo }\end{array}$ & & $\begin{array}{c}\text { Blood eosinophil } \\
\text { thresholds }\end{array}$ \\
\cline { 1 - 1 }$(\mathrm{N}=402 / 412)$ & & $\geq 150 \mathrm{cells} / \mu \mathrm{L}$ \\
$(\mathrm{N}=165 / 177)$ & & $\geq 300 \mathrm{cells} / \mu \mathrm{L}$ \\
$(\mathrm{N}=53 / 67)$ & $\geq 500 \mathrm{cells} / \mu \mathrm{L}$ \\
$(\mathrm{N}=53 / 42)$ & $<150 \mathrm{cells} / \mu \mathrm{L}$ \\
& $(\geq 300$ cells $/ \mu \mathrm{L}$ in prior year $)$
\end{tabular}

Exacerbations leading to ED visit/hospitalization

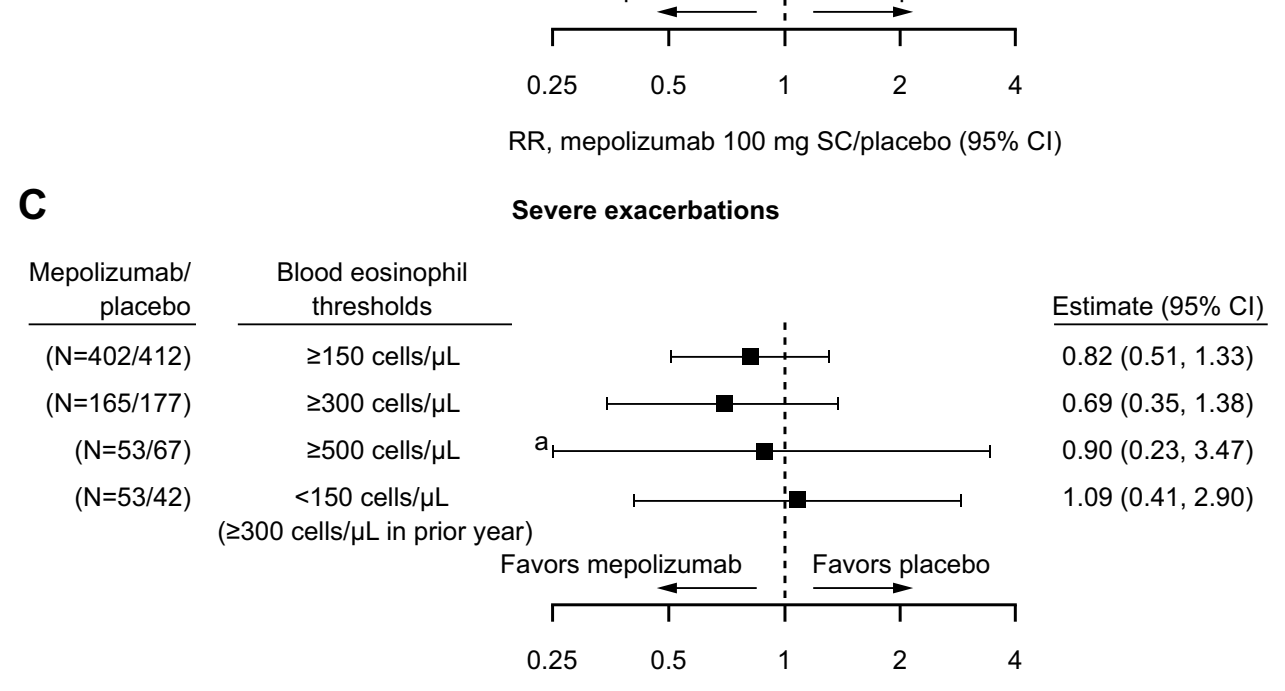

RR, mepolizumab $100 \mathrm{mg} \mathrm{SC/placebo} \mathrm{(95 \%} \mathrm{Cl)}$

Figure 4 Stratification (non-mutually exclusive) by screening blood eosinophil count thresholds of annual rates of $(\mathbf{A})$ moderate/severe exacerbations, (B) exacerbations leading to ED visit/hospitalization and (C) severe exacerbations at Week 52. Mepolizumab/placebo $\mathrm{N}$ numbers refer to the total patient numbers fulfilling the blood eosinophil count threshold criteria in the mepolizumab and placebo groups, respectively; one patient from the mepolizumab $100 \mathrm{mg}$ and one patient from the placebo group did not have a screening eosinophil count available. ${ }^{\mathrm{a}} \mathrm{Cl}$ extends beyond the $\mathrm{x}$-axis range.

Abbreviations: $\mathrm{Cl}$, confidence interval; $\mathrm{ED}$, emergency department; $\mathrm{RR}$, rate ratio; SC, subcutaneous.

reaching the MCID, mepolizumab- versus placebo-treated patients were significantly more likely to be CAT responders and rated objectively by clinicians to be in a higher improvement-response category at Week 52. Overall, these results are supportive of the potential for mepolizumab to reduce aspects of disease burden.
Trends for improvements in severe exacerbation frequency and CAT scores with increasing blood eosinophil counts were less clear than for other endpoints. This effect is likely to be attributable to the rarity of severe exacerbations and that changes in CAT score may be less differentiable by screening blood eosinophil count. Interestingly, patients who 
A

\begin{tabular}{rcc}
$\begin{array}{r}\text { Mepolizumab/ } \\
\text { placebo }\end{array}$ & & $\begin{array}{c}\text { Blood eosinophil } \\
\text { thresholds }\end{array}$ \\
\cline { 1 - 1 }$(\mathrm{N}=359 / 328)$ & & $\geq 150 \mathrm{cells} / \mu \mathrm{L}$ \\
$(\mathrm{N}=149 / 143)$ & & $\geq 300 \mathrm{cells} / \mu \mathrm{L}$ \\
$(\mathrm{N}=49 / 53)$ & $\geq 500 \mathrm{cells} / \mu \mathrm{L}$ \\
$(\mathrm{N}=42 / 31)$ & $<150 \mathrm{cells} / \mu \mathrm{L}$ \\
& $(\geq 300$ cells $/ \mu \mathrm{L}$ in prior year
\end{tabular}

SGRQ total score

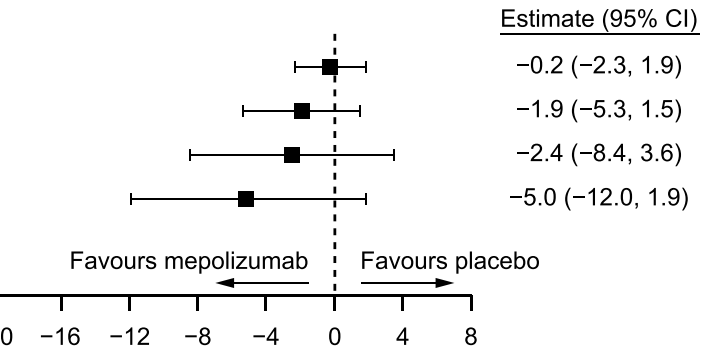

Difference, mepolizumab $100 \mathrm{mg} \mathrm{SC}$-placebo $(95 \% \mathrm{Cl})$

B

\begin{tabular}{rcc}
$\begin{array}{r}\text { Mepolizumab/ } \\
\text { placebo }\end{array}$ & & $\begin{array}{c}\text { Blood eosinophil } \\
\text { thresholds }\end{array}$ \\
\cline { 1 - 1 }$(\mathrm{N}=395 / 405)$ & & $\geq 150 \mathrm{cells} / \mathrm{\mu L}$ \\
$(\mathrm{N}=161 / 175)$ & & $\geq 300 \mathrm{cells} / \mathrm{\mu L}$ \\
$(\mathrm{N}=53 / 65)$ & & $\geq 500 \mathrm{cells} / \mu \mathrm{L}$ \\
$(\mathrm{N}=52 / 42)$ & $<150 \mathrm{cells} / \mu \mathrm{L}$
\end{tabular}

SGRQ responders ${ }^{a}$

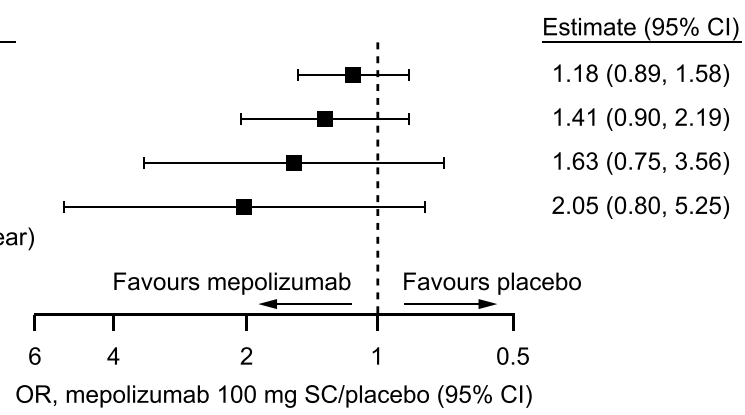

CAT score

C

\begin{tabular}{rcc}
$\begin{array}{r}\text { Mepolizumab/ } \\
\text { placebo }\end{array}$ & & $\begin{array}{c}\text { Blood eosinophil } \\
\text { thresholds }\end{array}$ \\
\cline { 1 - 2 }$(\mathrm{N}=344 / 319)$ & & $\geq 150$ cells $/ \mu \mathrm{L}$ \\
$(\mathrm{N}=140 / 136)$ & & $\geq 300 \mathrm{cells} / \mu \mathrm{L}$ \\
$(\mathrm{N}=48 / 52)$ & & $\geq 500 \mathrm{cells} / \mu \mathrm{L}$ \\
$(\mathrm{N}=40 / 31)$ & & $<150 \mathrm{cells} / \mu \mathrm{L}$
\end{tabular}
$(\geq 300$ cells $/ \mu \mathrm{L}$ in prior year)
Estimate $(95 \% \mathrm{Cl})$

$-0.5(-1.4,0.4)$

$-1.5(-2.9,-0.1)$

$-0.8(-3.2,1.6)$

$-4.9(-7.8,-2.1)$

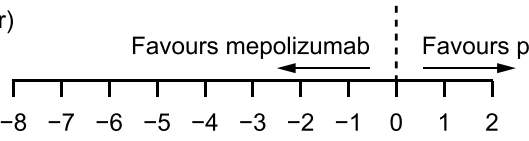

Difference, mepolizumab $100 \mathrm{mg}$ SC-placebo $(95 \% \mathrm{Cl})$

D

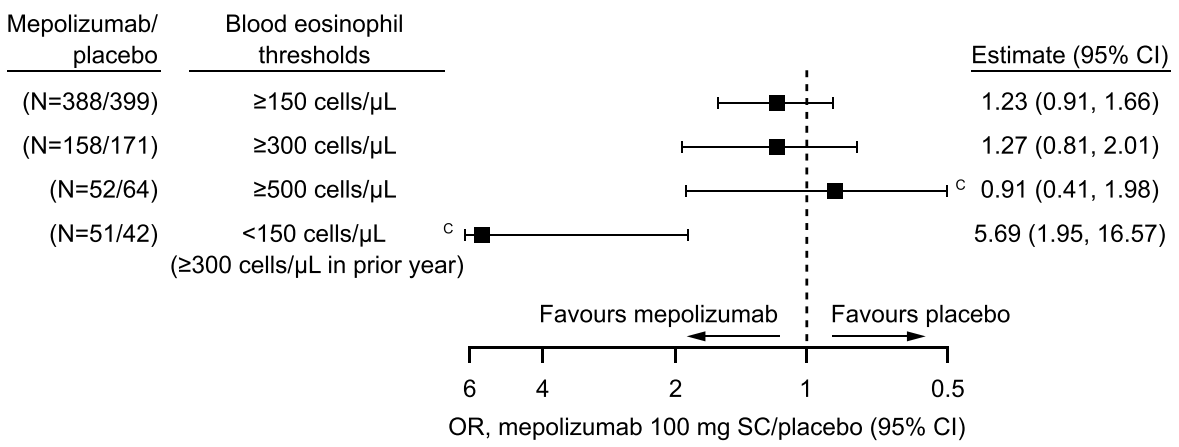

Figure 5 Week 52 change from baseline versus placebo for (A) SGRQ total score, (B) SGRQ responders, (C) CAT score, and (D) CAT responders by blood eosinophil count thresholds (non-mutually exclusive). Mepolizumab/placebo $\mathrm{N}$ numbers refer to the total patient numbers fulfilling the blood eosinophil count threshold criteria in the mepolizumab and placebo groups, respectively; one patient from the mepolizumab $100 \mathrm{mg}$ and one patient from the placebo group did not have a screening eosinophil count available; includes patients with endpoint measurements at baseline and Week 52. Panels B and D: patients with no endpoint measurement at Week 52 included as non-responders. aSGRQ responders are defined by $\geq 4$-point reduction in SGRQ total score; bCAT responders are defined by $\geq 2$-point reduction in the CAT score; $c \mathrm{Cl}$ extends beyond the $\mathrm{x}$-axis range.

Abbreviations: CAT, COPD Assessment Test; Cl, confidence interval; COPD, chronic obstructive pulmonary disease; OR, odds ratio; SC, subcutaneous; SGRQ, St George's Respiratory Questionnaire. 
A

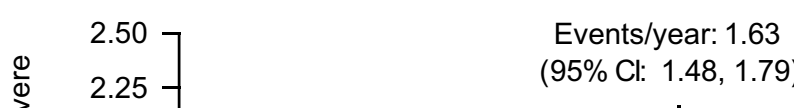

Events/year: 1.77

(95\% Cl: $1.56,2.02)$
Events/year: 1.89

(95\% Cl: 1.61, 2.21)

Events/year: 1.44

(95\% Cl: $1.31,1.58)$

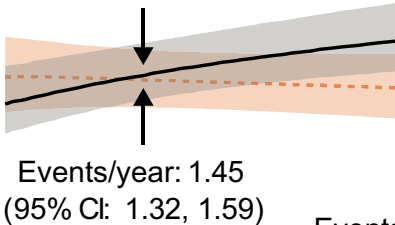

(95\% Cl: $1.26,1.56)$

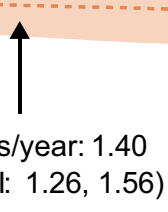

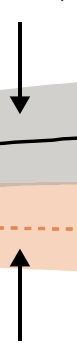

Events/year: 1.36

(95\% Cl: $1.18,1.58)$

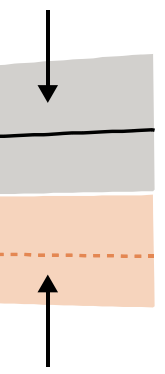

Events/year: 1.33

(95\% Cl: $1.10,1.60)$

0.50

Placebo $(\mathrm{N}=645)$

Mepolizumab $100 \mathrm{mg} \mathrm{SC} \mathrm{(N=640)}$

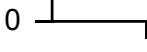

100

200

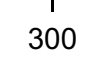

Blood eosinophils at screening (cells $/ \mu \mathrm{L})$

B

1.4
1.2
1
0.8
0.6
0.4

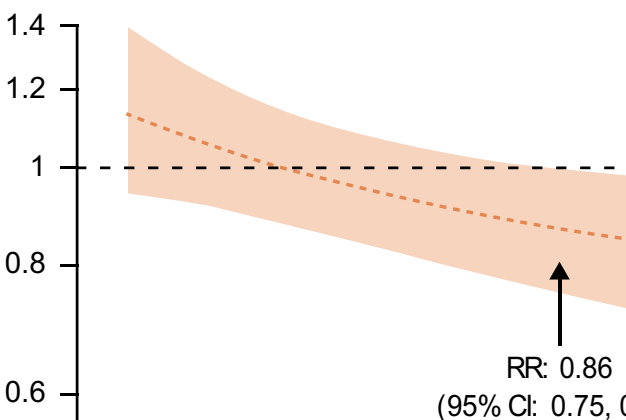

(95\% Cl: $0.75,0.99)$

-...- Model estimated rate ratio

1
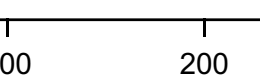

300

Blood eosinophils at screening (cells $/ \mu \mathrm{L}$ )

Figure 6 Predicted (A) annual rates and (B) treatment RR of all moderate/severe exacerbations by screening blood eosinophil count for patients receiving mepolizumab $100 \mathrm{mg} \mathrm{SC}$ or placebo (modelling analysis). Shaded areas represent $95 \%$ Cls for predicted rates and RRs; For (B), arrows represent events/year and RR at a screening eosinophil count threshold.

Abbreviations: $\mathrm{Cl}$, confidence interval; $\mathrm{RR}$, rate ratio; SC, subcutaneous.

exhibited screening eosinophil counts $<150$ cells $/ \mu \mathrm{L}$ and entered the trials with a historical count $\geq 300$ cells $/ \mu \mathrm{L}$ in the past year exhibited the greatest reductions in annual rates of moderate/severe exacerbations and greatest HRQoL improvements. This suggests that a historical increase in eosinophils may be important in determining mepolizumabresponsive individuals.

Limitations of this meta-analysis relate to limitations of the original trials. The possibility of a clinical-trial effect leading to increased adherence to background ICS-based triple inhaled therapy due to monthly study visits, and symptom monitoring via daily diary that may lead to earlier identification of exacerbations, could explain the observed reductions in moderate/severe exacerbation rates/year in the placebo group during the study compared with the prior year. This would make the impact of mepolizumab on infrequent exacerbation events, such as exacerbations leading to an ED visit/hospitalization, more difficult to detect. The smoking 

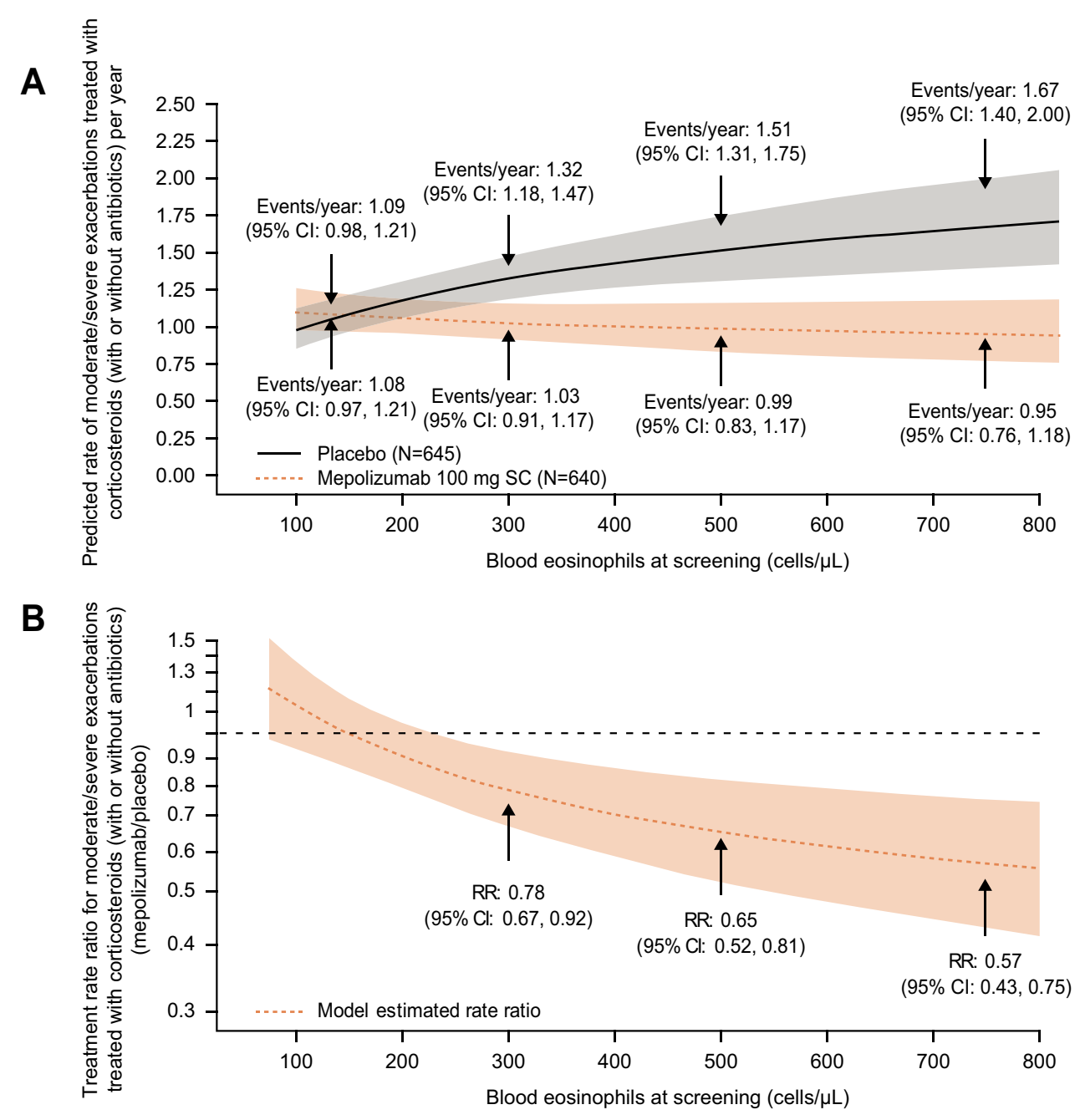

$\underbrace{}_{\substack{\text { Mepolizumab/ } \\ \text { placebo }}}$

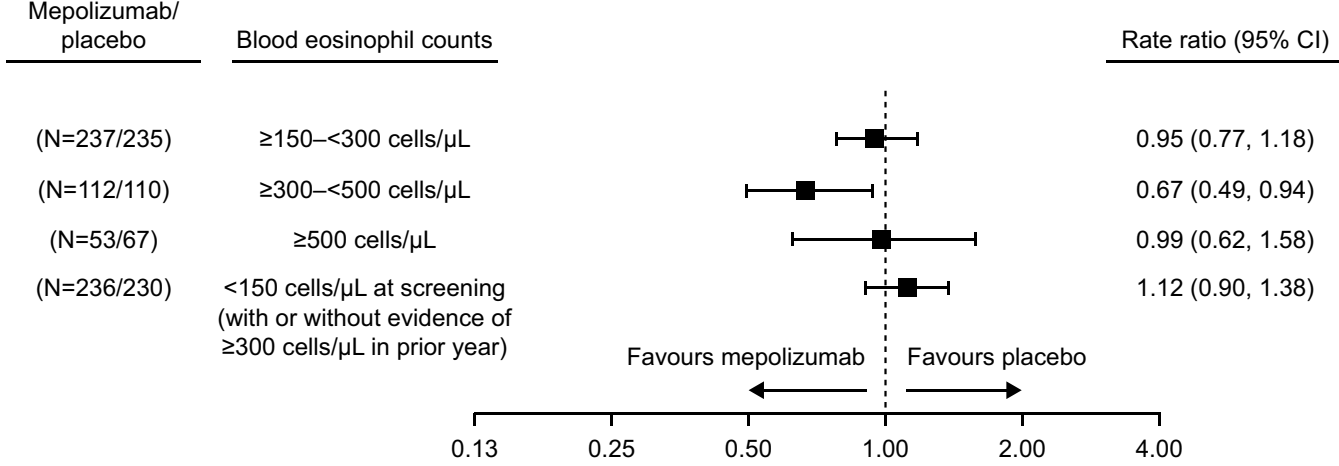

RR for moderate/severe exacerbations treated with corticosteroids (with or without antibiotics) mepolizumab $100 \mathrm{mg} \mathrm{SC} /$ placebo $(95 \% \mathrm{Cl})$

Figure 7 Predicted (A) annual rates and (B) RR of moderate/severe exacerbations treated with corticosteroids (with and without antibiotics) by screening blood eosinophil count (modelling analysis); (C) stratification (mutually exclusive) by screening blood eosinophil count categories of annual rates of moderate/severe exacerbations requiring antibiotics (with and without OCS). Shaded area represents $95 \% \mathrm{Cls}$ for predicted rates and RRs; arrows represent events/year and RR at a screening eosinophil count threshold. Panel C: two patients from the mepolizumab $100 \mathrm{mg}$ and three patients from the placebo group did not have a screening eosinophil count available.

Abbreviations: $\mathrm{Cl}$, confidence interval; RR, rate ratio; OCS, oral corticosteroid; SC, subcutaneous. 
criteria employed were also different from most COPD studies, where smoking history is generally an eligibility requirement. As approximately $20 \%$ of patients with COPD have no history of smoking, ${ }^{43}$ METREX and METREO allowed non-smokers in the study to better represent the realworld COPD population. All patients were required to meet accepted spirometry parameters for COPD, have a documented history of COPD exacerbations in the year prior to study initiation and required confirmation by the study physician that there was no history of asthma. Therefore, it is unlikely that the $\sim 3 \%$ of the total study population who were non-smokers would have had undiagnosed asthma. Furthermore, treatment outcomes with mepolizumab were similar when these patients were excluded. Finally, the inclusion of patients in this analysis who prematurely discontinued treatment may have biased results, although, as the total percentage of the study population who discontinued was small $(8 \%)$ and balanced across treatment groups (7-9\% per group), this is unlikely to have influenced results.

In summary, COPD is a heterogenous disease and, without biomarkers, it is difficult to tailor treatments to patients. Data from this meta-analysis show that the use of blood eosinophil counts allows for the identification of patients with COPD who continue to experience exacerbations while treated with maximal ICS-based triple maintenance therapy who are responsive to anti-IL-5 treatment. Mepolizumab treatment benefits on reducing exacerbations and decreasing aspects of disease burden were clearest in patients with blood eosinophil counts $\geq 300$ cells/ $\mu \mathrm{L}$, suggesting that this population requires further investigation.

\section{Data Sharing Statement}

Data are available upon reasonable request: Anonymized individual participant data and study documents for the original METREX and METREO studies can be requested for further research from www.clinicalstudydatarequest.com.

\section{Ethics Approval and Informed Consent}

All the patients provided written informed consent for METREX and METREO. Both METREX and METREO were conducted in accordance with the ethical principles of the Declaration of Helsinki, the International Conference on Harmonization. Good Clinical Practice guidelines and the applicable country-specific regulatory requirements. A full list of the ethics committees for each study is provided in the Supplementary Materials.

\section{Acknowledgments}

Editorial support (in the form of writing assistance, including preparation of the draft manuscript under the direction and guidance of the authors, collating and incorporating authors' comments for each draft, assembling tables and figures, grammatical editing and referencing) was provided by Alex Lowe, PhD, and Mary E. Morgan, PhD, of Fishawack Indicia Ltd, UK, Part of Fishawack Health, and was funded by GlaxoSmithKline (GSK). Abstracts describing the results of this analysis were presented at the American Thoracic Society and European Respiratory Society International Conferences in 2018 as a poster presentation. The posters' abstracts were published in the American Journal of Respiratory and Critical Care Medicine (Bafadhel et al, Am J Respir Crit Care Med 2018;197:A5912. Chapman et al, Am J Respir Crit Care Med 2018;197:A4230) and the European Respiratory Journal (Pavord et al, Eur Respir J. 2018;52(Suppl 62): PA1992).

\section{Author Contributions}

SSH, BM, DBR and SWY made substantial contributions to study concept and design; MB, KRC, IDP, FCS, SSH, $\mathrm{BM}$ and PP made substantial contributions to data acquisition; MB, KRC, IDP, FCS, ESB, SSH, BM, DBR, SWY and PP made substantial contributions to data analysis and interpretation. All authors took part in drafting the article or revising it critically for important intellectual content; agreed to submit to the current journal; gave final approval of the version to be published; and agree to be accountable for all aspects of the work.

\section{Funding}

GlaxoSmithKline (GSK meta-analysis ID 207478, Integrated Summary of Efficacy [ISE] 207577, and the individual parent studies [117106/NCT02105948 and 117113/NCT02105961]).

\section{Disclosure}

MB has received honoraria from AstraZeneca, Boehringer Ingelheim, Chiesi, GSK and Novartis and has received independent/institutional grant support from Pfizer and AstraZeneca. KRC reports grants and personal fees from AstraZeneca, Boehringer Ingelheim, CSL Behring, 
Grifols, Sanofi, Genentech, Kamada, Mereo Biopharma, Regeneron, Roche and Novartis; grants from Baxter, GSK, Vertex, and Amgen; and personal fees from Merck, Takeda. He also holds a Canadian Institute of Health Research-GSK research chair in Respiratory Health Care Delivery at the University Health Network. In the last 5 years, IDP received funding from the NIHR as a Senior Investigator; he has received speaker's honoraria for speaking at sponsored meetings from AstraZeneca, Boehringer Ingelheim, Aerocrine, Almirall, Menarini, Novartis, Teva, Chiesi and GSK and payments for organizing educational events from AstraZeneca and Teva. He has received honoraria for attending advisory panels with Genentech, Regeneron, AstraZeneca, Boehringer Ingelheim, GSK, Novartis, Teva, Merck, Sanofi, Circassia, Chiesi and Knopp. He has received sponsorships to attend international scientific meetings from Boehringer Ingelheim, GSK, AstraZeneca, Teva and Chiesi. He has also received a grant from Chiesi to support a Phase II clinical trial in Oxford. In addition, IDP has a patent Leicester Cough Questionnaire with royalties paid. FCS received grants from the National Institutes of Health, Patient-Centered Outcomes Research Institute, the COPD Foundation, the US Department of Defense, Astellas, AstraZeneca, Boehringer Ingelheim, GSK, Phillips Respironics, PulmonX, PneumRx and Spiration; and personal fees from Circassia, Boehringer Ingelheim, GSK and PneumRx. ESB was an employee of GSK and holds GSK stock/shares during the conduct of the study, his current affiliation is Aeglea BioTherapeutics, Austin, Texas. SWY is an employee of GSK and hold GSK stock/ shares. DBR was an employee of GSK and holds GSK stocks/shares during the conduct of the study, his current affiliation is DBR Consulting LLC, Raleigh NC. SSH was an employee of GSK and holds GSK stocks/shares during the conduct of the study. All authors received nonfinancial support from GSK in the form of editorial support. PP reports personal fees from GlaxoSmith Kline, during the conduct of the study; grants and/or personal fees from AstraZeneca, Chiesi, Novartis, and Sanofi, outside the submitted work. The authors report no other conflicts of interest in this work.

\section{References}

1. Brightling CE, Monteiro W, Ward R, et al. Sputum eosinophilia and short-term response to prednisolone in chronic obstructive pulmonary disease: a randomised controlled trial. Lancet. 2000;356 (9240):1480-1485. doi:10.1016/S0140-6736(00)02872-5
2. Saha S, Brightling CE. Eosinophilic airway inflammation in COPD. Int J Chron Obstruct Pulmon Dis. 2006;1(1):39-47. doi:10.2147/ copd.2006.1.1.39

3. Bafadhel M, McKenna S, Terry S, et al. Acute exacerbations of chronic obstructive pulmonary disease: identification of biologic clusters and their biomarkers. Am J Respir Crit Care Med. 2011;184(6):662-671. doi:10.1164/rccm.201104-05970C

4. Bafadhel M, McCormick M, Saha S, et al. Profiling of sputum inflammatory mediators in asthma and chronic obstructive pulmonary disease. Respiration. 2012;83(1):36-44. doi:10.1159/000330667

5. Bartoli ML, Costa F, Malagrino L, et al. Sputum inflammatory cells in COPD patients classified according to GOLD 2011 guidelines. Eur Repir J. 2016;47(3):978-980. doi:10.1183/13993003.00784-2015

6. Brightling CE, McKenna S, Hargadon B, et al. Sputum eosinophilia and the short term response to inhaled mometasone in chronic obstructive pulmonary disease. Thorax. 2005;60(3):193-198. doi:10.1136/thx.2004.032516

7. Singh D, Kolsum U, Brightling CE, et al. Eosinophilic inflammation in COPD: prevalence and clinical characteristics. Eur Respir J. 2014;44(6):1697-1700. doi:10.1183/09031936.00162414

8. Kolsum U, Damera G, Pham TH, et al. Pulmonary inflammation in patients with chronic obstructive pulmonary disease with higher blood eosinophil counts. J Allergy Clin Immunol. 2017;140 (4):1181-1184.e1187. doi:10.1016/j.jaci.2017.04.027

9. Bafadhel M, McKenna S, Pickering S, et al. The sensitivity and specificity of peripheral blood eosinophilia to predict sputum eosinophilia in COPD subjects. Am J Respir Crit Care Med. 2009;129: A1479.

10. Negewo NA, McDonald VM, Baines KJ, et al. Peripheral blood eosinophils: a surrogate marker for airway eosinophilia in stable COPD. Int J Chron Obstruct Pulmon Dis. 2016;11:1495-1504. doi:10.2147/COPD.S100338

11. Pignatti P, Visca D, Cherubino F, et al. Do blood eosinophils strictly reflect airway inflammation in COPD? Comparison with asthmatic patients. Respir Res. 2019;20(1):145. doi:10.1186/s12931-019-1111-1

12. Bafadhel M, McKenna S, Terry S, et al. Blood eosinophils to direct corticosteroid treatment of exacerbations of chronic obstructive pulmonary disease: a randomized placebo-controlled trial. Am J Respir Crit Care Med. 2012;186(1):48-55. doi:10.1164/rccm.201108-1553OC

13. Pascoe S, Locantore N, Dransfield MT, Barnes NC, Pavord I. Blood eosinophil counts, exacerbations, and response to the addition of inhaled fluticasone furoate to vilanterol in patients with chronic obstructive pulmonary disease: a secondary analysis of data from two parallel randomised controlled trials. Lancet Respir Med. 2015;3(6):435-442. doi:10.1016/S2213-2600(15)00106-X

14. Pavord ID, Agusti A. Blood eosinophil count: a biomarker of an important treatable trait in patients with airway disease. Eur Respir $J$. 2016;47(5):1299-1303. doi:10.1183/13993003.00055-2016

15. Varricchi G, Bagnasco D, Borriello F, Heffler E, Canonica GW. Interleukin-5 pathway inhibition in the treatment of eosinophilic respiratory disorders: evidence and unmet needs. Curr Opin Allergy Clin Immunol. 2016;16(2):186-200. doi:10.1097/ACI.0000000000000251

16. Hartl S, Breyer MK, Burghuber OC, et al. Blood eosinophil count in the general population: typical values and potential confounders. Eur Respir J. 2020;55(5):1901874. doi:10.1183/13993003.1390187413992019.

17. Pavord ID, Korn S, Howarth P, et al. Mepolizumab for severe eosinophilic asthma (DREAM): a multicentre, double-blind, placebo-controlled trial. Lancet. 2012;380(9842):651-659. doi:10.1016/S0140-6736(12)60988-X

18. Chupp GL, Bradford ES, Albers FC, et al. Efficacy of mepolizumab add-on therapy on health-related quality of life and markers of asthma control in severe eosinophilic asthma (MUSCA): a randomised, double-blind, placebo-controlled, parallel-group, multicentre, phase 3b trial. Lancet Respir Med. 2017;5(5):390-400. doi:10.1016/S2213-2600(17)30125-X 
19. Ortega HG, Yancey SW, Mayer B, et al. Severe eosinophilic asthma treated with mepolizumab stratified by baseline eosinophil thresholds: a secondary analysis of the DREAM and MENSA studies. Lancet Respir Med. 2016;4(7):549-556. doi:10.1016/S22132600(16)30031-5

20. Ortega HG, Liu MC, Pavord ID, et al. Mepolizumab treatment in patients with severe eosinophilic asthma. N Engl J Med. 2014;371 (13):1198-1207. doi:10.1056/NEJMoa1403290

21. Yancey SW, Ortega HG, Keene ON, et al. Meta-analysis of asthma-related hospitalization in mepolizumab studies of severe eosinophilic asthma. J Allergy Clin Immunol. 2017;139(4):1167-1175. e1162. doi:10.1016/j.jaci.2016.08.008

22. Chapman KR, Bergeron $\mathrm{C}$, Bhutani $\mathrm{M}$, et al. Do we know the minimal clinically important difference (MCID) for COPD exacerbations? COPD. 2013;10(2):243-249. doi:10.3109/ 15412555.2012 .733463

23. Dasgupta A, Kjarsgaard M, Capaldi D, et al. A pilot randomised clinical trial of mepolizumab in COPD with eosinophilic bronchitis. Eur Respir J. 2017;49(3):1602486. doi:10.1183/13993003.1390248613992016.

24. Celli BR, MacNee W. ATS/ERS Task Force. Standards for the diagnosis and treatment of patients with COPD: a summary of the ATS/ ERS position paper. Eur Respir J. 2004;23(6):932-946. doi:10.1183/ 09031936.04 .00014304

25. Jones PW. Interpreting thresholds for a clinically significant change in health status in asthma and COPD. Eur Respir J. 2002;19 (3):398-404. doi:10.1183/09031936.02.00063702

26. Kon SS, Canavan JL, Jones SE, et al. Minimum clinically important difference for the COPD Assessment Test: a prospective analysis. Lancet Respir Med. 2014;2(3):195-203. doi:10.1016/S2213-2600(14) 70001-3

27. Yun JH, Lamb A, Chase R, et al. Blood eosinophil count thresholds and exacerbations in patients with chronic obstructive pulmonary disease. J Allergy Clin Immunol. 2018;141(6):2037-2047.e2010. doi:10.1016/j.jaci.2018.04.010

28. Zeiger RS, Tran TN, Butler RK, et al. Relationship of Blood Eosinophil Count to Exacerbations in Chronic Obstructive Pulmonary Disease. J Allergy Clin Immunol in Practice. 2018;6 (3):944-954.e945. doi:10.1016/j.jaip.2017.10.004

29. Criner GJ, Celli BR, Singh D, et al. Predicting response to benralizumab in chronic obstructive pulmonary disease: analyses of GALATHEA and TERRANOVA studies. Lancet Respir Med. 2020;8(2):158-170. doi:10.1016/S2213-2600(19)30338-8

30. Wedzicha JA, Calverley PM, Seemungal TA, et al. The prevention of chronic obstructive pulmonary disease exacerbations by salmeterol/ fluticasone propionate or tiotropium bromide. Am J Respir Crit Care Med. 2008;177(1):19-26. doi:10.1164/rccm.200707-973OC

31. Vestbo J, Anderson JA, Brook RD, et al. Fluticasone furoate and vilanterol and survival in chronic obstructive pulmonary disease with heightened cardiovascular risk (SUMMIT): a double-blind randomised controlled trial. Lancet. 2016;387(10030):1817-1826. doi:10.1016/S0140-6736(16)30069-1
32. Calverley PM, Anderson JA, Celli B, et al. Salmeterol and fluticasone propionate and survival in chronic obstructive pulmonary disease. N Engl J Med. 2007;356(8):775-789. doi:10.1056/NEJMoa063070

33. Dransfield MT, Bourbeau J, Jones PW, et al. Once-daily inhaled fluticasone furoate and vilanterol versus vilanterol only for prevention of exacerbations of COPD: two replicate double-blind, parallel-group, randomised controlled trials. Lancet Respir Med. 2013;1(3):210-223. doi:10.1016/S2213-2600(13)70040-7

34. Lipson DA, Barnacle H, Birk R, et al. FULFIL trial: once-daily triple therapy for patients with chronic obstructive pulmonary disease. $\mathrm{Am}$ J Respir Crit Care Med. 2017;196(4):438-446. doi:10.1164/ rccm.201703-04490C

35. Wedzicha JA, Banerji D, Chapman KR, et al. Indacaterolglycopyrronium versus salmeterol-fluticasone for COPD. $N \mathrm{Engl}$ $J$ Med. 2016;374(23):2222-2234. doi:10.1056/NEJMoa1516385

36. Vestbo J, Leather D, Diar Bakerly N, et al. Effectiveness of fluticasone furoate-vilanterol for COPD in clinical practice. $N$ Engl J Med. 2016;375(13):1253-1260. doi:10.1056/NEJMoa1608033

37. Lipson DA, Barnhart F, Brealey N, et al. Once-daily single-inhaler triple versus dual therapy in patients with COPD. $N$ Engl J Med. 2018;378(18):1671-1680. doi:10.1056/NEJMoa1713901

38. Kerwin E, Hebert J, Gallagher N, et al. Efficacy and safety of NVA237 versus placebo and tiotropium in patients with COPD: the GLOW2 study. Eur Respir J. 2012;40(5):1106-1114. doi:10.1183/ 09031936.00040712

39. Wedzicha JA, Decramer M, Ficker JH, et al. Analysis of chronic obstructive pulmonary disease exacerbations with the dual bronchodilator QVA149 compared with glycopyrronium and tiotropium (SPARK): a randomised, double-blind, parallel-group study. Lancet Respir Med. 2013;1(3):199-209. doi:10.1016/S2213-2600(13) 70052-3

40. Morishita-Katsu M, Nishimura K, Taniguchi H, et al. The COPD assessment test and St George's Respiratory Questionnaire: are they equivalent in subjects with COPD? Int J Chron Obstruct Pulmon Dis. 2016;11:1543-1551. doi:10.2147/COPD.S104947

41. Tsiligianni IG, Alma HJ, de Jong C, et al. Investigating sensitivity, specificity, and area under the curve of the Clinical COPD Questionnaire, COPD Assessment Test, and Modified Medical Research Council scale according to GOLD using St George's Respiratory Questionnaire cutoff 25 (and 20) as reference. Int J Chron Obstruct Pulmon Dis. 2016;11:1045-1052. doi:10.2147/ COPD.S99793

42. Vestbo J, Anderson JA, Calverley PM, et al. Bias due to withdrawal in long-term randomised trials in COPD: evidence from the TORCH study. Clin Respir J. 2011;5(1):44-49. doi:10.1111/j.1752699X.2010.00198.x

43. Terzikhan N, Verhamme KM, Hofman A, Stricker BH, Brusselle GG, Lahousse L. Prevalence and incidence of COPD in smokers and non-smokers: the Rotterdam Study. Eur J Epidemiol. 2016;31 (8):785-792. doi:10.1007/s10654-016-0132-z 


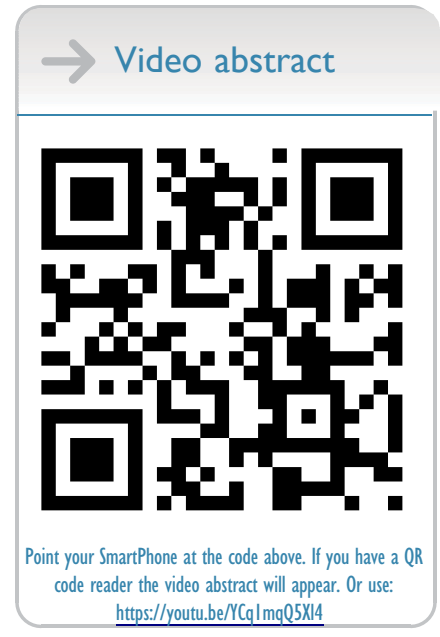

International Journal of Chronic Obstructive Pulmonary Disease

\section{Publish your work in this journal}

The International Journal of COPD is an international, peer-reviewed journal of therapeutics and pharmacology focusing on concise rapid reporting of clinical studies and reviews in COPD. Special focus is given to the pathophysiological processes underlying the disease, intervention programs, patient focused education, and self management protocols. This journal is indexed on PubMed Central, MedLine and CAS. The manuscript management system is completely online and includes a very quick and fair peer-review system, which is all easy to use. Visit http://www.dovepress.com/testimonials.php to read real quotes from published authors. 